\title{
Application of Virtual Reality and Plant Modeling for Participation in Urban Planning and Design
}

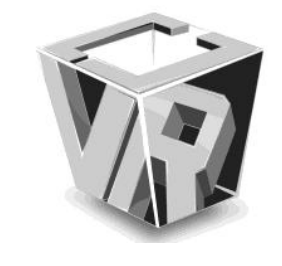

\author{
Enmi Lim, Kiyoshi Umeki and Tsuyoshi Honjo
}

\author{
Graduate School of Horticulture, Chiba University
}

\begin{abstract}
In landscape planning, visualization of landscape is a powerful tool for public understanding and for selection of alternative plans. In recent years, three dimensional (3D) computer graphics (CG) were used as visualization tools of environment because it has the ability to accurately simulate the changes caused by a proposed plan. In particular, virtual reality (VR), which enables to walk through in a modeled park or in a visualized forest, was considered as the advanced technique of landscape visualization.

In this study, we developed a landscape visualization system with graphic user interface, which we named VR-Terrain (GUI version), to generate the virtual reality image easily by using VRML (Virtual Reality Modeling Language) and plant modeling techniques. In order to test the feasibility of the landscape visualization system, we applied the system to Ichinoe Urban Design Plan. Ichinoe is located at Edogawa Ward, Tokyo. There is a Sakaikawa Shinsui Park with water space surrounded by large amount of green. In the case study, we simulated the landscape of Sakaikawa Shinsui Park with about 200 plants and 300 buildings. We used the images simulated by VR-Terrain to explain the concept (such as building height limit) to the residents in the public meetings. It took about 30 hours to make the 3D model of the town. After ten minutes of training, anybody can walk through in the simulated town freely. The results showed that the VR image by the system helped the public understanding of the concept of the urban plan.
\end{abstract}

Index Terms - Landscape planning and design, Visualization, VRML, Plant Modeling, Participation

\section{INTRODUCTION}

In the landscape simulation, reality of the simulated image is very important and recent advances in computer visualization technology allowed us to simulate and visualize natural complex forms and phenomena such as plant growth and effects of changes in atmospheric condition and light [5], [25].

Since 1980's, the improvement in computer technology and digital plant modeling enabled photo-realistic and high quality simulation of landscape [7], [20]. Many researchers simulated realistic landscape images using plant modeling since Honjo et al. (1992) proposed the application of the 3D plant modeling to the landscape simulation [8]. Saito et al. (1993) made the photo-realistic simulation images of forest landscapes [24]. Morimoto (1993) simulated historical Japanese gardens [18].

Manuscript received on 12 July 2008

E-Mail: honjo@ faculty.chiba-u.jp
Honjo and Takeuchi (1995) generated the images of the campus landscape [9]. These researches showed that application of the plant modeling to the landscape simulation was very effective. In these cases of landscape simulation by a plant modeling, static images were mainly used because the number of polygons that comprised simulated scenery was very large.

In the next step of the landscape visualization, walk-through animation or real time rendering of landscape were desired and application of virtual reality (VR) technique was considered as one of the solutions [8]. VR, which enables to walk through in a modeled park or in a visualized forest, was expected as the advanced technique of landscape visualization [2], [5], [22].

Several VR systems were developed as tools for landscape planning. Orland et al. (1994) developed SmartForest system which is a visualization tool for forest landscape [21]. Raper et al. (1998) made virtual environments by linking aerial video images to map and by showing 3D terrain model in real time [23]. Danahy (2001) showed a panoramic presentation system by using computers (Silicon Graphics O2) synchronized on a network and Liquid Crystal Display (LCD) projectors [2]. This system displayed real-time panoramic images of modeled landscape and allowed the viewer to have immersive experiences within a displayed scene. Bishop et al. (2001) developed a VR system capable of conducting an assessment of path choices on a country walk [1].

Many researchers also developed 3D terrain visualization systems by using Virtual Reality Modeling Language (VRML), which is a high performance language for $3 \mathrm{D}$ visualization on the World Wide Web (WWW) and 3D information can be easily transferred through the Internet. Fairbairn and Parsley (1997) introduced VRML for cartographic presentation [6]. Honjo and Takeuchi (1998) developed a visualization system of 3D terrain using VRML [10]. They showed the possibility of VRML as a language for 3D visualization of landscape. Moore et al. (1999) developed a 3D terrain visualization system by using Java and VRML for students to experience field work environments through VR [17]. Huang and Lin (1999) developed a 3D terrain visualization system called GeoVR by linking VRML with GIS [12]. GeoVR enabled the conversion of the data of 2D GIS into VRML format. Lin et al. [16] presented four practical solutions (i.e. using VRML and Java, Java and Java3D, VRML and ActiveX and Java wrapper classes) for 3D terrain visualization. They showed that employing VRML was a good way to model multi-dimensional data sets. Huang and Lin (2002) developed a geographic VR toolkit by using VRML, Java and common gateway interface (CGI) [13]. 
Doyle et al (1998) discussed the potential of VR technologies including VRML for the visualization [4]. Morrison and Purves (2002) showed examples of VR technologies including VRML for 3D terrain visualization [19].

Application of VR for landscape assessment has been few because of the difficulty of making and operating the VR systems until Honjo \& Lim (2001) developed a system for real-time rendering of landscape by using VRML and plant modeling techniques [11]. Landscapes of parks, gardens and forests with thousands of plants were simulated by using the landscape visualization system called VR-Terrain [11], [14]. Lim, et al. (2006) conducted landscape assessment experiment both on the Internet and in the laboratory by using VRML images made by VR-Terrain as a stimulus [15]. The results of the experiments showed that the VRML images can be used as an effective stimulus for landscape assessment. VR-Terrain showed good performance and it also indicated the potential of building a VR system by VRML with very low cost. However, the system proved inadequate for presenting urban landscapes including various types of houses and buildings. In this study, we developed a landscape visualization system with graphic user interface, which we named VR-Terrain (GUI version), to generate the VR image easily. In order to test the feasibility of the landscape visualization system, we applied the system to the real process of the Urban Design plan.

\section{PRocedure OF LANDSCAPE VISUALIZATION BY VRML}

VRML is one of the Web3d technologies, which are used deliver interactive 3D objects and worlds across the Internet. VRML 1.0 was introduced in 1994 and VRML 2.0 (97) with more dynamic and interactive functions was made in 1996. GeoVRML and X3D, which are the successors of VRML, are currently being developed. Several Web3d technologies such as Pulse3D, Cult3D, Viewpoint and Shockwave3D etc. are developed or being developed now but only VRML can be practically used for walk-through simulation. By using VRML and plant modeling techniques, we developed a virtual reality system that enabled virtual experience in a modeled landscape. In this study, VRML 2.0 was used to develop the present system. Cortona (ParallelGraphics Inc.) was used as a VRML browser with Internet Explorer 6 (Microsoft Inc.) on Windows (Microsoft Inc.). To write and run VRML code only a VRML browser and Internet browser are required.

Basic elements of landscape are plants and terrain. The procedures of the visualization of landscapes by VRML are shown in Fig. 1. The visualization procedure consists of three steps. The first step is the collection of the 3D data of plants and terrain. Vegetation data (the species, size and age of trees, etc.) can be obtained from a vegetation map or a field survey. The terrain data can be obtained from contours of the map or digital terrain model (DTM) of the simulated area. In the second step, the data of plants and terrain are transformed into VRML format by using 'VR-Terrain'. VR-Terrain was developed in Visual Basic (Microsoft Inc.). In the final step, the VRML image of the landscape is generated on the user's computer and the user can have an experience of a walk-through simulation in the modeled landscape. to

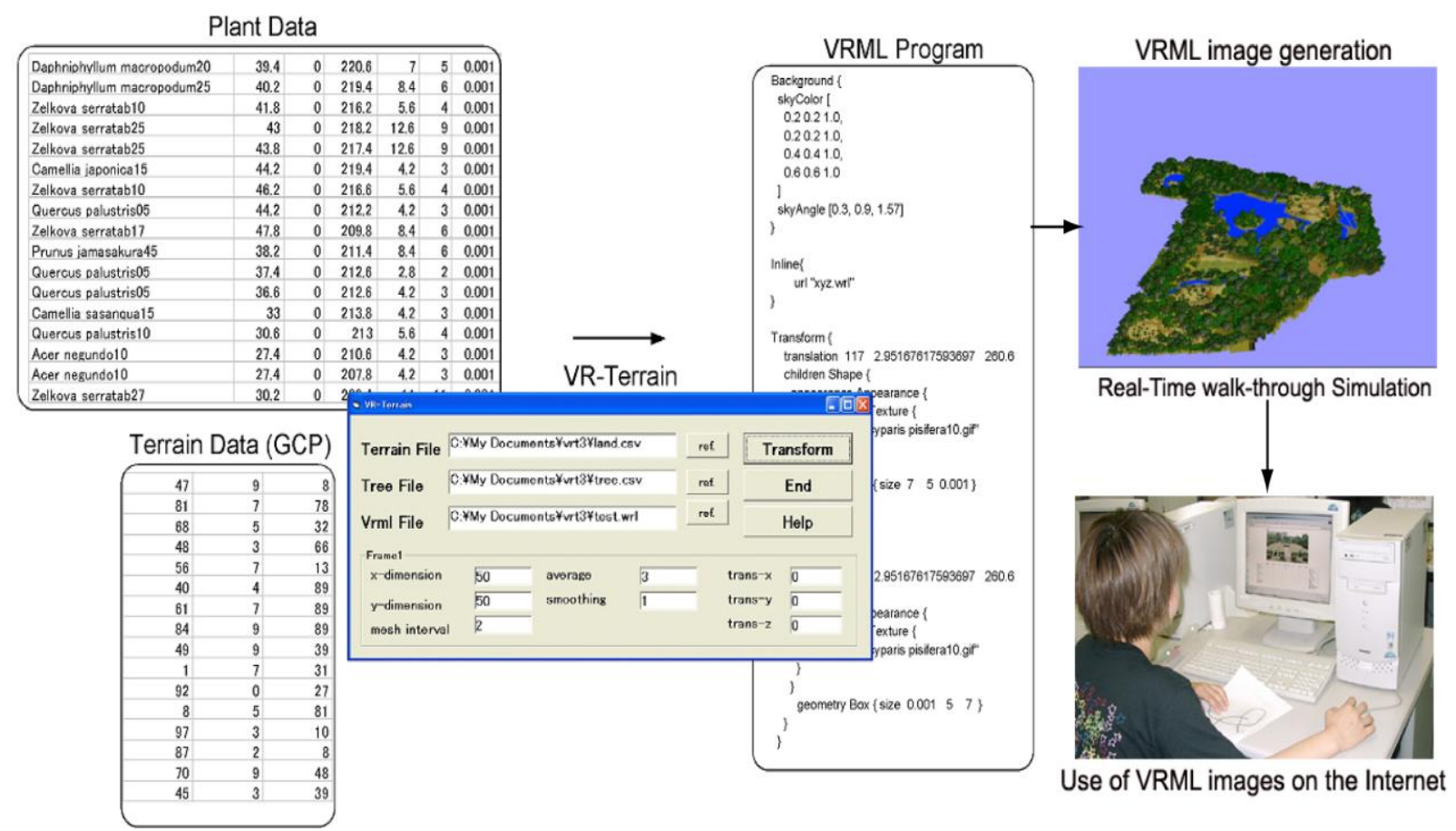

Fig. 1 Procedures of the visualization of landscapes by VRML 


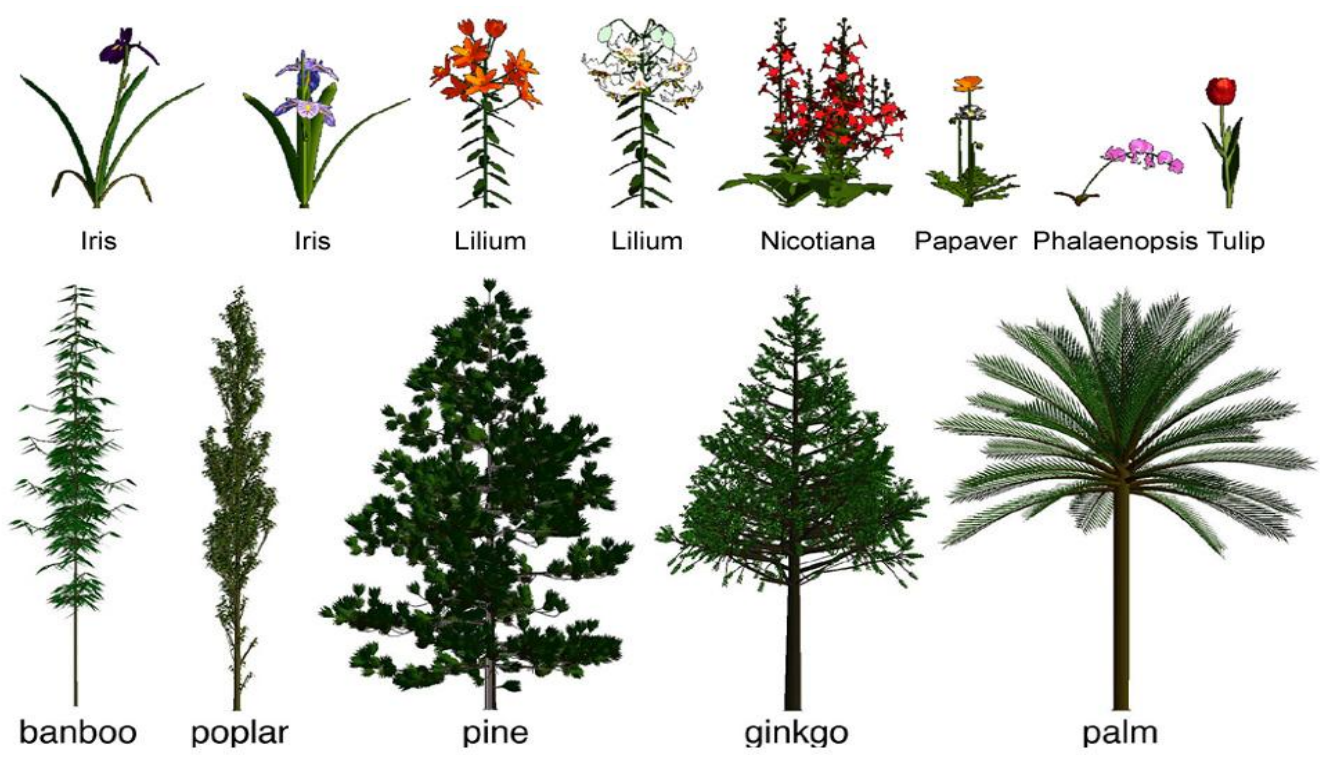

(a) Example of 3D Plants made by AMAP

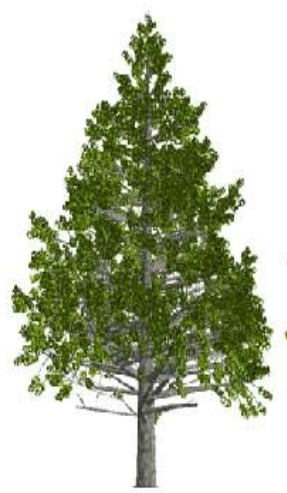

Summer

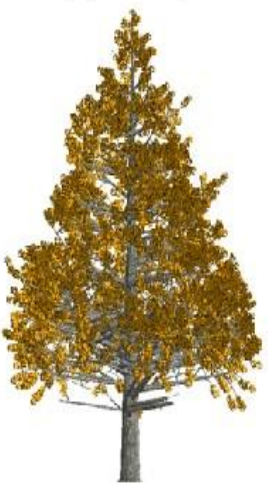

Autumn

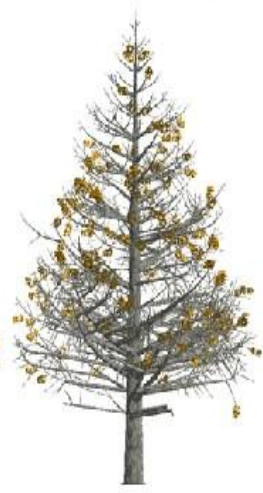

Winter

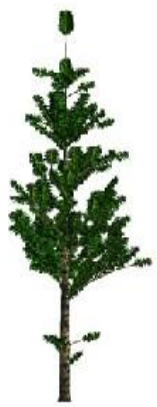

Before

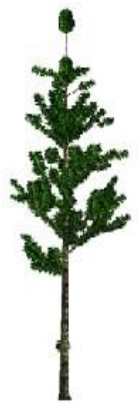

After

(b) Seasonal effect made by AMAP (Ginkgo biloba L.) $\quad$ (c) Pruning effect made by AMAP(Abies firma Sieb et Zucc.)

Fig. 2 Example of Plants made by AMAP

The textures of plants, which are in a transparent GIF format, are mapped on a plane and two planes are crossed to show the plants. We used two-dimensional (2D) computer graphics images of plants made by AMAP (Atelier de Modelisation de Architecture de Plants). AMAP is a CAD system for landscape design, which includes high-precision 3D plant modeling technique [3]. AMAP can model more than 300 types of plants, including flowers, bushes, and trees. The AMAP system can also generate $3 \mathrm{D}$ model at different ages of a given plant and at different times of the year. Pruning is possible by AMAP (Fig. 2). AMAP also generates different shapes for the same plant by changing the seed number of a plant. Using 2D images made by AMAP, we can easily simulate a variety of landscapes.

\section{GUI VERSION OF VR-TERRAIN}

In this study, we developed an advanced version of VR-Terrain for the visualization of urban landscapes with graphic user interface. With the system, which we named GUI version of VR-Terrain, VRML models of landscapes can be generated very effectively. In Fig. 3, interface of VR-Terrain is shown. The system has some layers for terrain, building, tree and generate VRML. In the main window of VR-Terrain, we select a background image of the study area and input the width scale of the image.

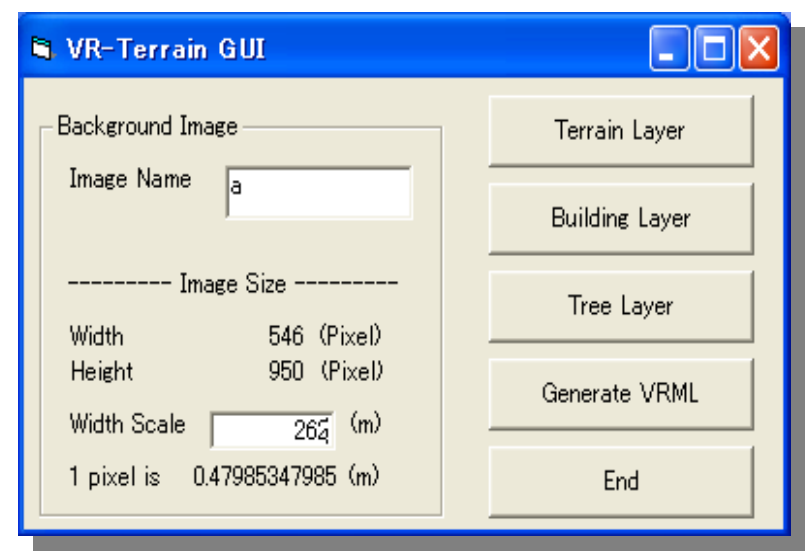

Fig. 3 Main menu of VR-Terrain 


\subsection{Terrain layer}

In Fig. 4, the Terrain layer consists of a TerrainMenu window (Fig. 4 (a)) and a GCP location window (Fig. 4 (b)). In order to make a terrain 3D model, we input the value of the elevation of the contours of the background image on the TerrainMenu window, and then coordinates (x, y) of GCP (Ground Control Point) were obtained by clicking the mouse along the contours on the GCP location window. The value (x, $\mathrm{y}, \mathrm{z}$ ) of the GCP was recorded on the menu window of terrain layer. Terrain data was saved as the CSV (Comma Separated Value) format. By clicking the button of 'VRML' on the menu window, the data was transformed into VRML format. We confirmed the accuracy of the obtained terrain data immediately with the VRML image simulated in the terrain layer (Fig. 4 (c)).

In VR-Terrain, grid data for elevation was calculated by interpolation method and equation as shown in Fig. 5. In the

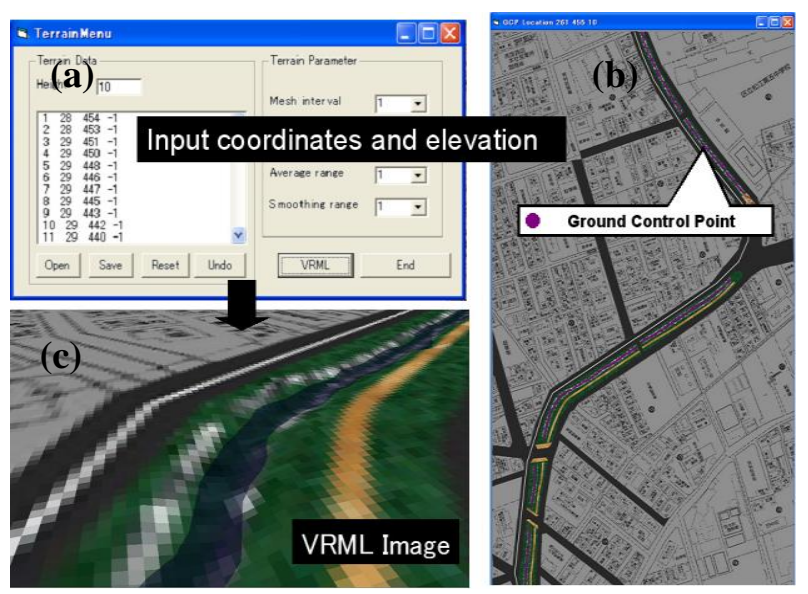

Fig. 4 Terrain Layer

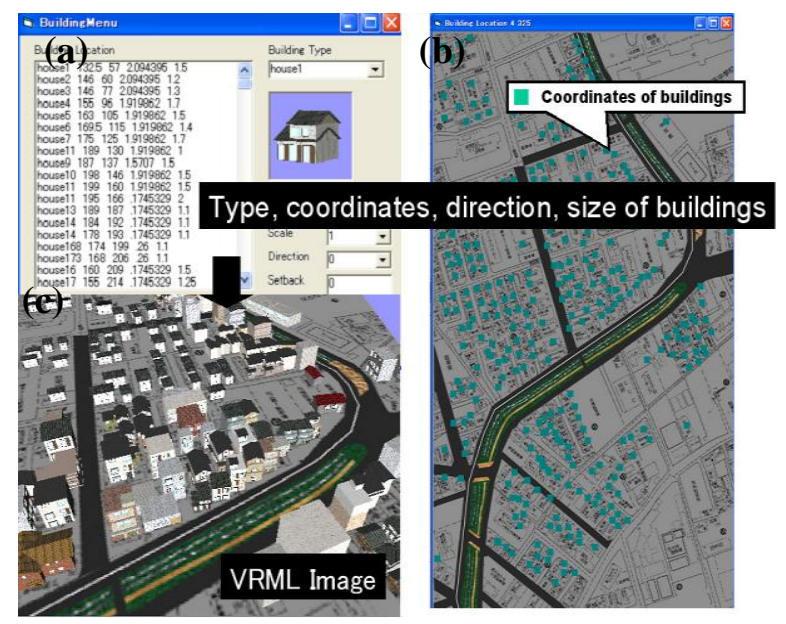

Fig. 6 Building Layer
TerrainMenu window, users choose the size of grid mesh by changing the mesh interval.

\subsection{Building layer}

In Fig. 6, the Building layer consists of a BuildingMenu window (Fig. 6 (a)) and a Building location window (Fig. 6 (b)). In the Building layer, objects were effectively placed by using GUI as shown in Fig. 6. We selected the type, the direction and the size of a building on the menu window of building layer. The coordinates of buildings were obtained and recorded such as the terrain layer. Buildings data was saved as the CSV format. By clicking the button of 'VRML' on the menu window, the buildings data was transformed into VRML format. In this study, we used a texture mapping to increase building realism instead of coloring a building by varying the amount of red, blue and green in the RGB values.

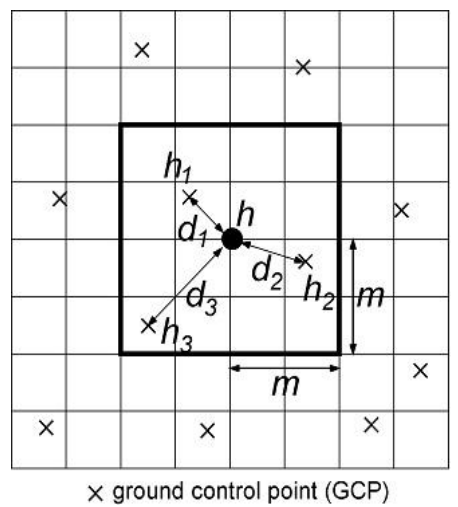

$h=\frac{\sum_{i} h_{i} \cdot d_{i}^{-1}}{\sum_{i} d_{i}^{-1}}$

Equation used to interpolate measured GCP

$h$ is elevation of the calculated grid, $h i$ is a elevation of GCP and $d i$ is a distance from point of $h$ to point of $h i$. When used control points are located in $2 \times m$ square grid, $m=2$ and $i=3$.

Fig. 5 Interpolation Method of Elevation Data in VR-Terrain
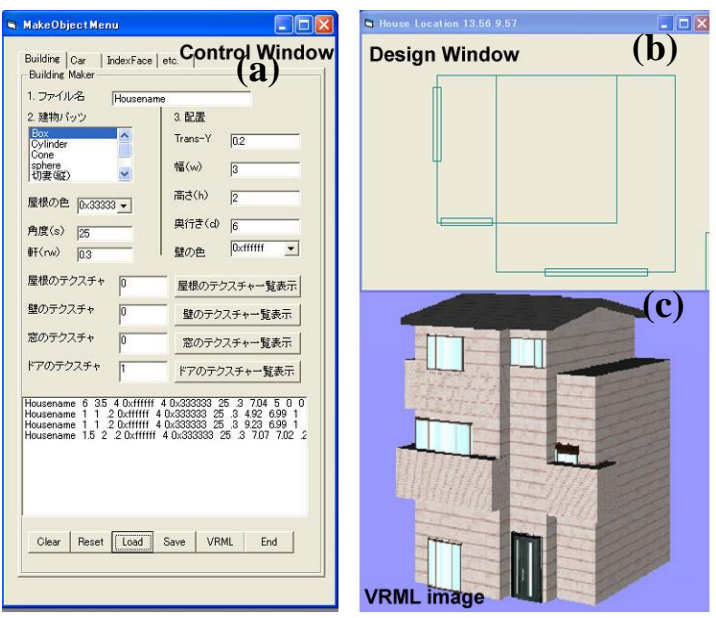

Fig. 7 House-maker 

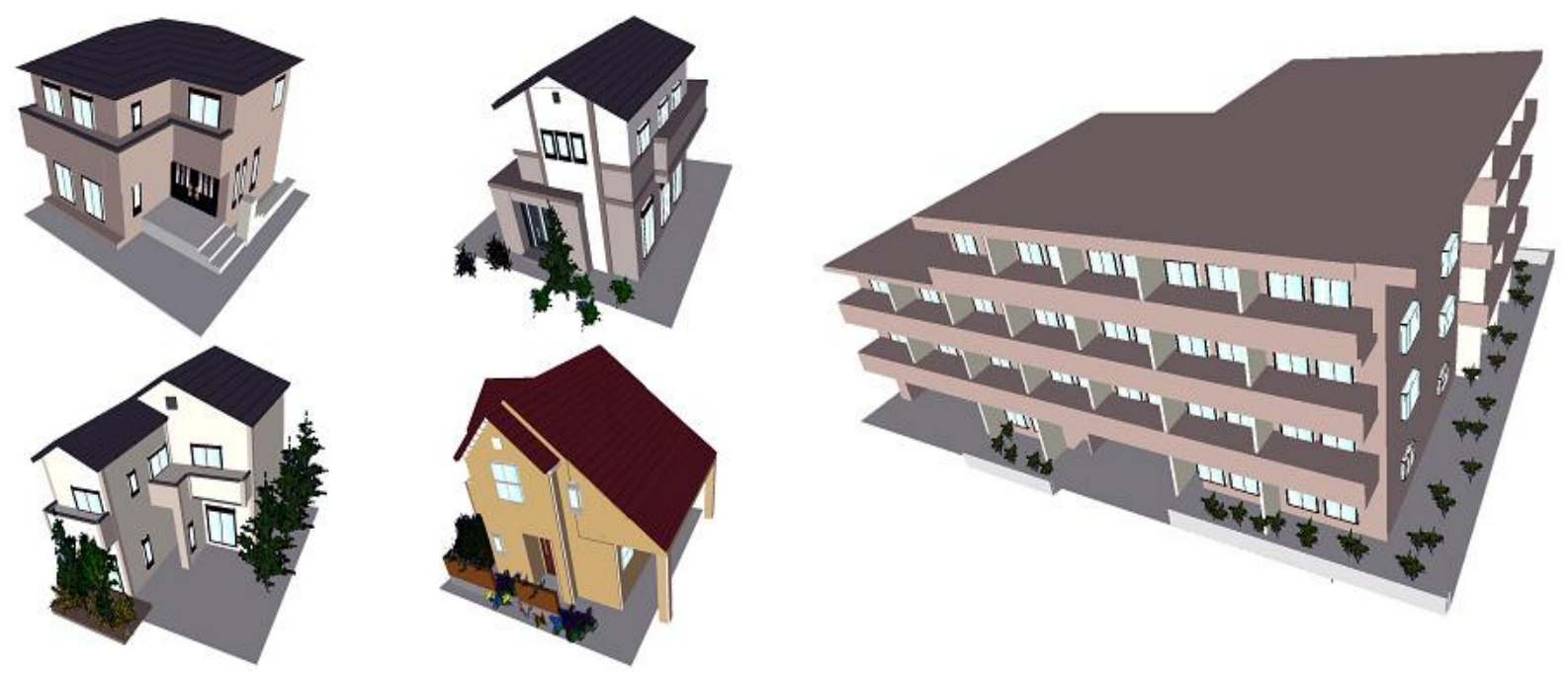

Fig. 8 Examples of houses and buildings made by House-maker

To design buildings used in Building layer, we developed House-maker as shown in Fig. 7. House-maker consists of a control window and a design window. We decided the shape, the texture and the size of buildings such as roof, window and wall on the control window (Fig. 7(a)). The parts of the buildings selected on the control window were constructed with the top perspective view on the design window (Fig. 7(b)). Finishing the design of the building, we confirmed the building with the VRML image (Fig. 7(c)). By using house-maker, we generated any type of architecture, from small housed to skyscrapers in the layer of building. Examples of houses and buildings are shown in Fig. 8. It is possible to manage Level of Detail (LOD) by changing the resolution of the texture on the building.

\subsection{Tree layer}

In Fig. 9, the Tree layer has two windows, same as the Building layer. In the Tree layer when there is the tree file recorded the species, age, location, height and width of trees, trees are easily visualized by using the tree file. When there is no tree data, we make a tree file by using the GUI as shown in Fig. 9. We selected the tree image on the TreeMenu window Fig. 9 (a). The coordinate $(x, y)$ of the tree was obtained by clicking the mouse on the Tree location window Fig. 9 (b). When there weren't the species of planned plants, we used the plant image of similar shape and size. When we selected the tree image suitable to its age from the image database.

The 2D plant images to provide plant textures were made from 3D images of AMAP. Examples of plant images are shown in Fig. 10. We made a plant image database including flowers (35 species), shrub (50 species) and trees (50 species). We also made images of each plant at different ages.

\subsection{Generation of VRML File}

After the design of the scene is done, the VRML model is generated as shown in Fig. 11. With the VR-Terrain developed in this study, we model landscapes of residential area, urban and suburban area and natural forest. The data of terrain, tree and building are saved as the CSV file format and the XML file format.

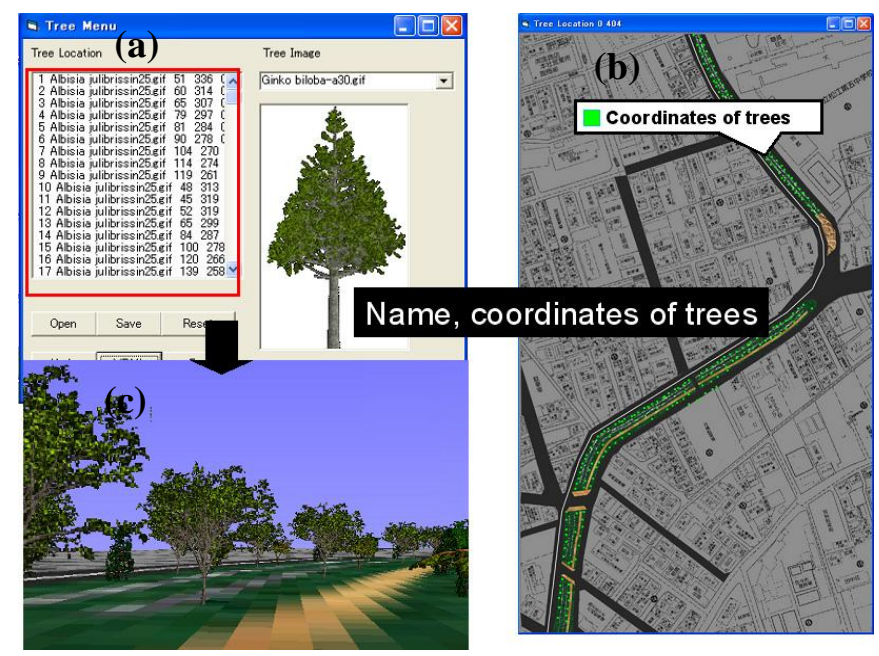

Fig. 9 Tree Layer

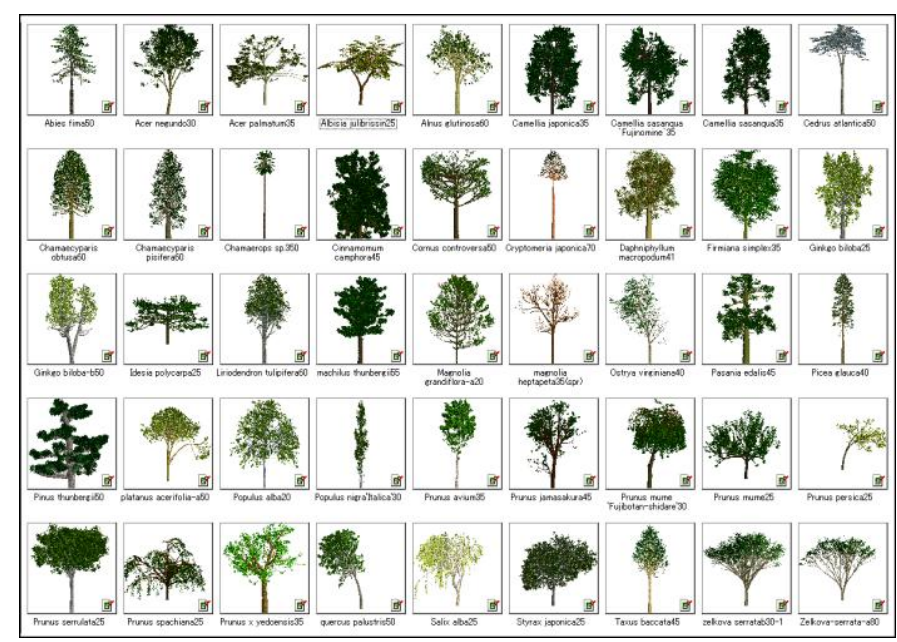

Fig. 10 Examples of plant images 


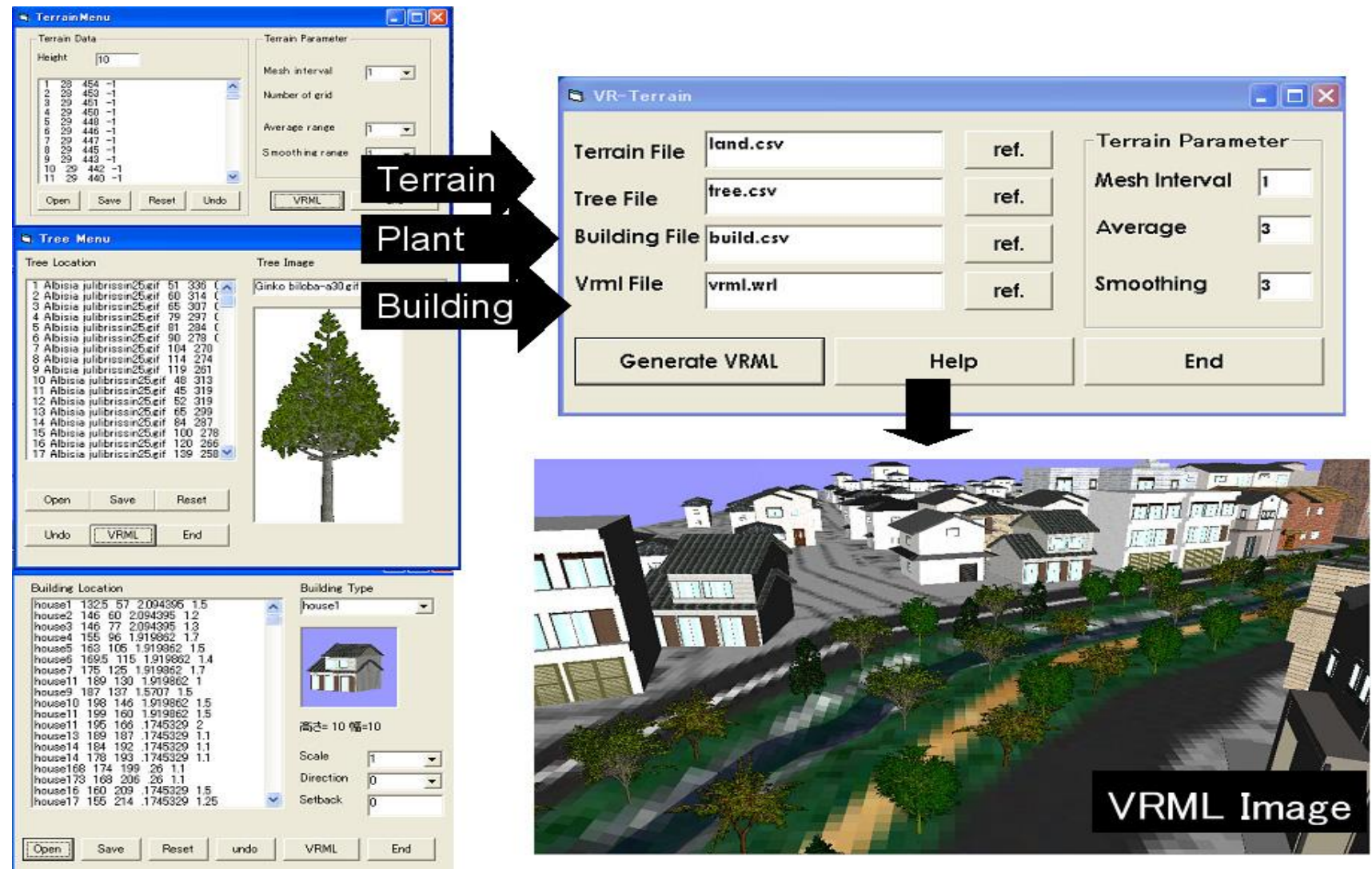

Fig. 11 Generate VRML Model
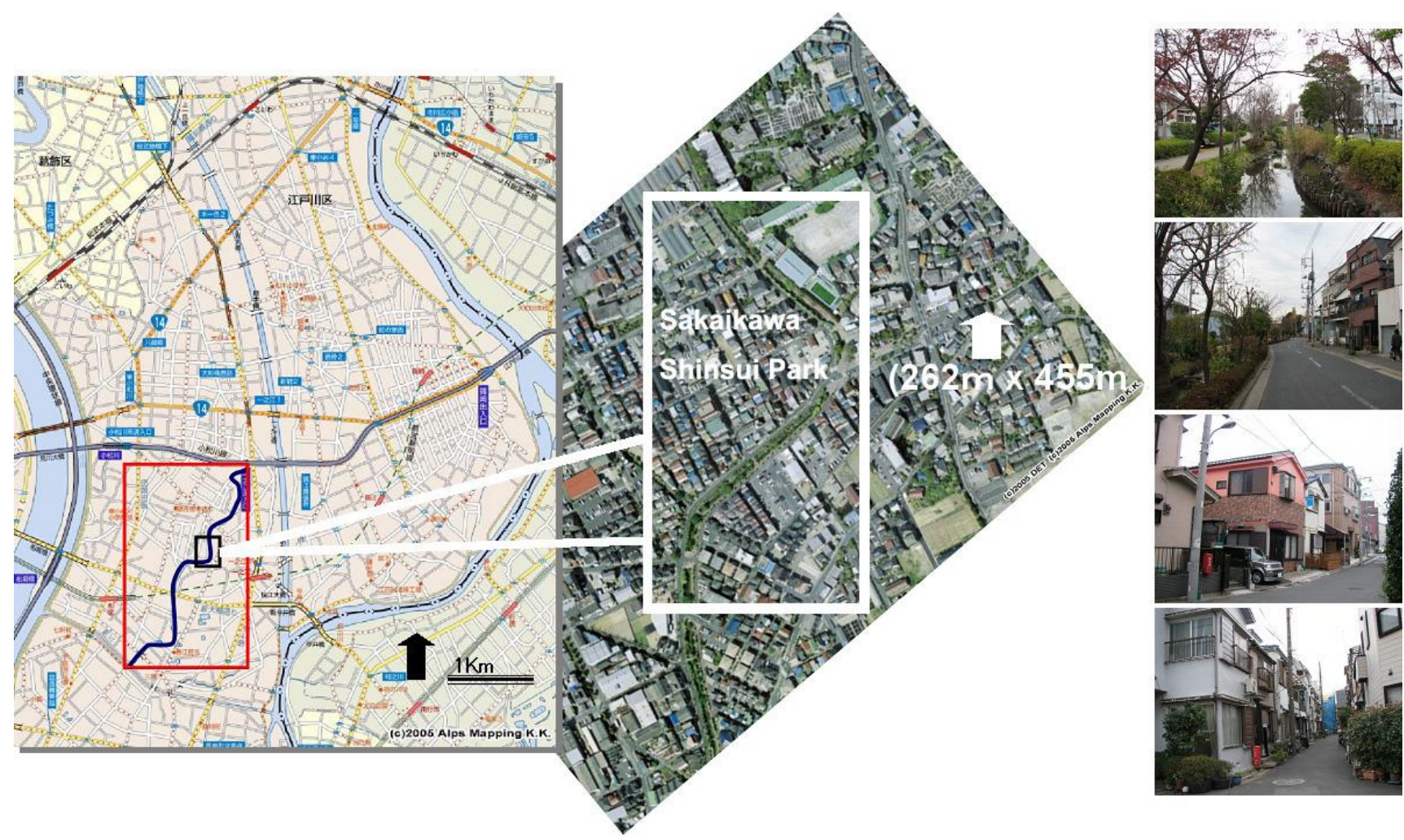

Fig. 12 Map, aerial photograph and photos of study area

(Sakaikawa Shinsui Park, Ichinoe, Edogawa Ward, Tokyo, About 12ha) 


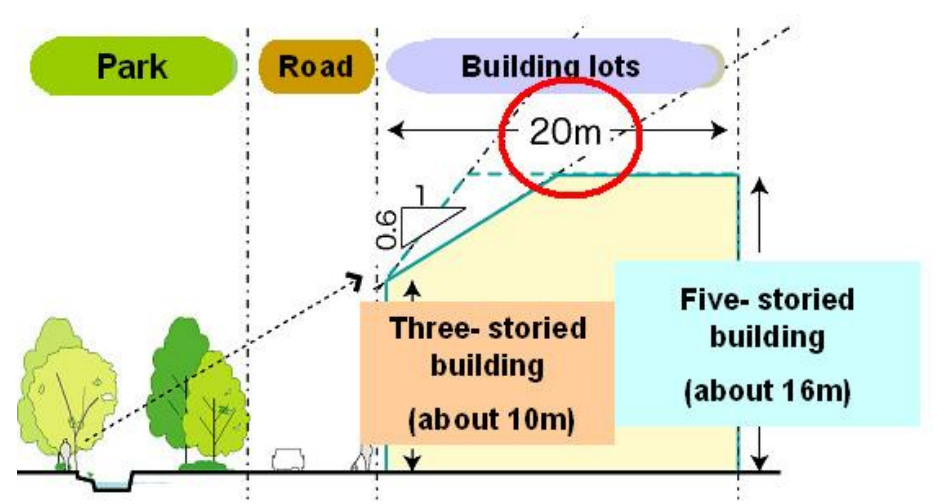

(a) Building height limit

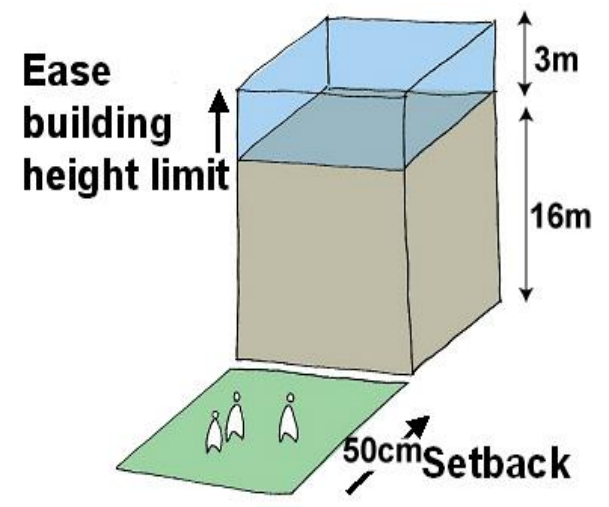

(b) Building setback

Fig. 13 Concept of building height limit and building setback considered in Ichinoe Urban Design Plan

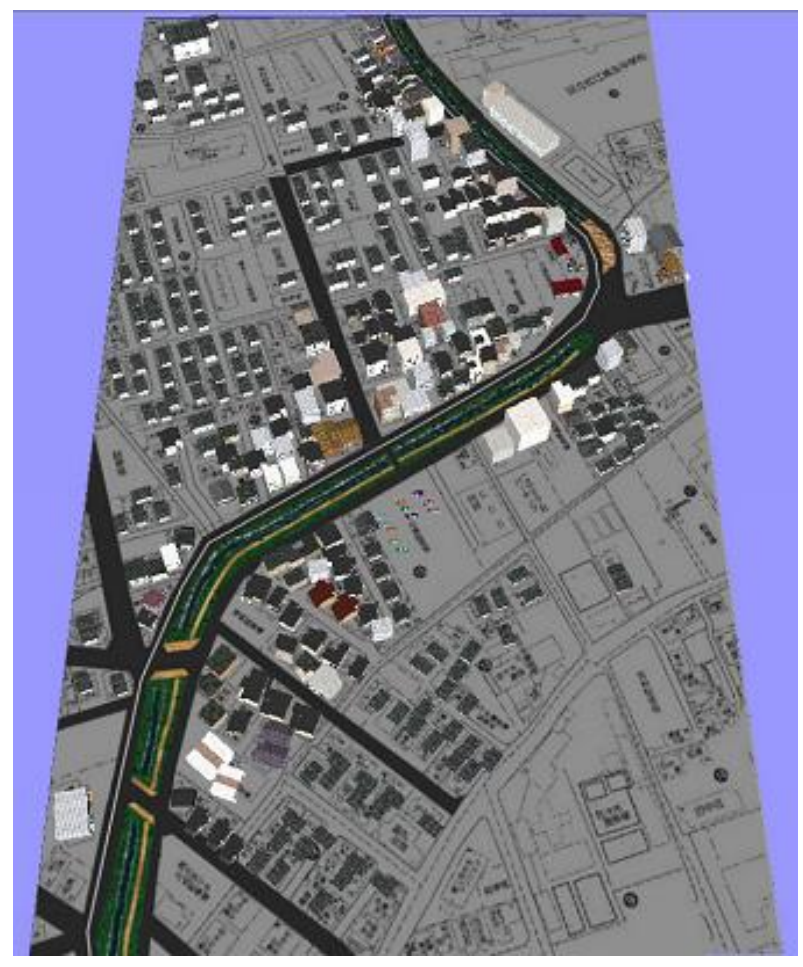

Fig. 14 VRML image of the study area

\section{APPLICATION OF VRML FOR PARTICIPATION IN URBAN PLANNING AND DESIGN}

\subsection{Study area}

In order to test the feasibility of VR-Terrain, we applied the system to Ichinoe Urban Design Plan. Ichinoe is located at Edogawa Ward, Tokyo. In Fig. 12 the map, the aerial photograph and photos of Ichinoe are shown. There is a Sakaikawa Shinsui Park with water space surrounded by large amount of green as shown in Fig. 12. The public meeting for Ichinoe Urban Design Plan had been started to discuss the regulation to preserve good scenery of Ichinoe since August 2004. Building regulation such as building height limit (Fig.
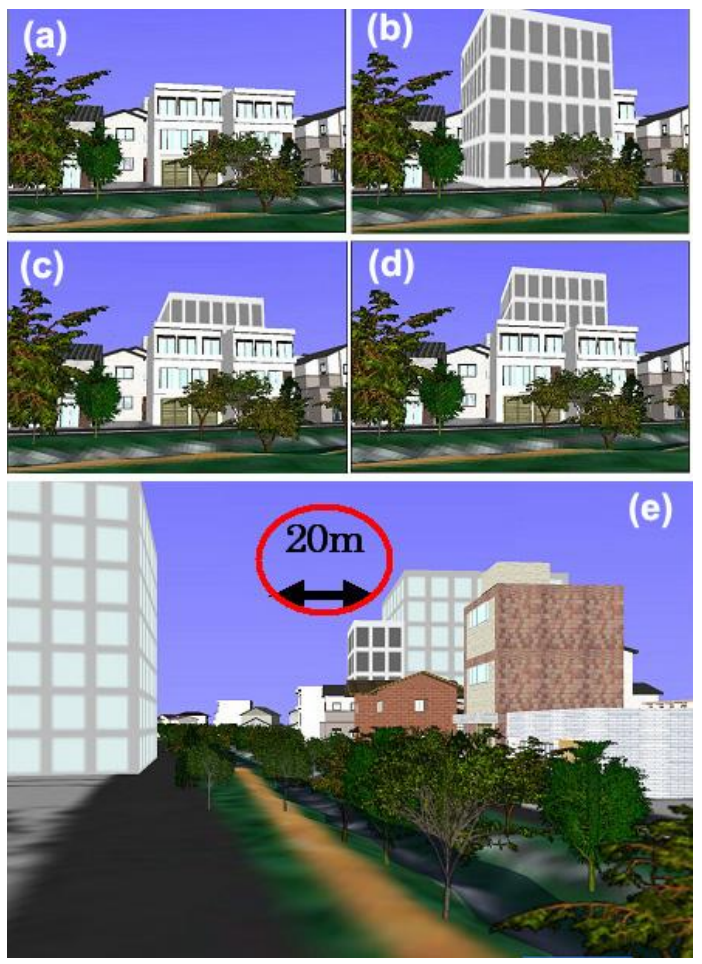

Fig. 15 Consideration of the building regulation using VRML images

13(a)) and building setback (Fig. 13(b)) was discussed in Ichinoe Urban Design Plan. In the roadside area, building height was limited to $10 \mathrm{~m}$ (3 stories). In the other areas, building height was allowed up to $16 \mathrm{~m}$ (5 stories). The regulation of building height was eased from $16 \mathrm{~m}$ to $19 \mathrm{~m}$ as an incentive to recompense for floor-area losses as a result of setback of building line with $50 \mathrm{~cm}$ from the roadside.

\subsection{Visualization of urban landscape by VR-Terrain}

In this study, we simulated the landscape of Sakaikawa Shinsui Park (262m x 456m) surrounded by a white square in Fig. 12 with about 200 plants and 300 buildings. It took about 30 hours for one person to make the 3D model of the town. Fig. 14 is bird's-eye view of the study area simulated by VR-Terrain. 
Initially, it took about a few seconds to generate the image whose screen resolution was $1600 \times 1200$ pixels, running on a Windows XP installed DirectX renderer with an AMD Athlon $2 \mathrm{GHz}, 1 \mathrm{~GB}$ of RAM and $128 \mathrm{MB}$ of Video card's Memory. The size of the VRML program was about $3.088 \mathrm{MB}$ (2.130MB VRML file for terrain, buildings and plants, $0.264 \mathrm{~KB}$ for texture data of terrain, $0.486 \mathrm{~KB}$ for texture data of buildings and $0.208 \mathrm{~KB}$ for texture data of plants). The images were rendered smoothly (about 5 frames per second) as the viewpoint was changed.

In Ichinoe Urban Design Plan the main objectives are to preserve the characteristics of Ichinoe, which has a Sakaikawa Shinsui Park with water space surrounded by large amount of green. In order to secure the enough sky, the local residents had opinions of keeping a current street that consisted of houses of from 2 to 3 stories. We simulated the images to explain the concept such as building height limit and building setback in Fig. 13. For the explanation in the public meeting, we made following simulation images. At first, we simulated a current street that consisted of houses of 2 stories or 3 stories as shown in Fig. 15 (a). We also simulated Fig. 15 (b) and showed walk-through simulation of the image, assuming that a building of 4 stories was constructed on the roadside. We simulated Fig. 15 (c), assuming that a building of 4 stories was constructed at 10 meter away from the roadside. Fig. 15 (d) was simulated, assuming that a building of 5 stories was constructed at 10 meter away from the roadside. Fig 15 (e) was simulated, assuming that a building of 5 stories was constructed at the back of a building of 4 stories.

With the walk-through simulation images from Fig. 15 (b) to Fig. 15 (e), we showed that the arrangement and height of buildings as shown in Fig. 15 (c), Fig. 15 (d) and Fig. 15 (e) could secure more enough sky than those of buildings as shown in Fig. 15 (b). We also confirmed that the arrangement and height of buildings of Fig. 15 (c), Fig. 15 (d) and Fig. 15 (e) made people feel less pressure than those of buildings of Fig. 15(b). Applying these results to the urban design, building height was limited to $10 \mathrm{~m}$ ( 3 stories) in the roadside area.

\subsection{Application of VRML for participation in urban planning and design}

The simulated images were used to explain the effect of building regulation to the residents in the public meetings as shown in Fig. 16. With a sequence of images of the walk-through simulations, we showed the local residents how to see each simulation image from different viewpoints. We could immediately simulate another image when we were asked to change the type of the building and the height of the building on the way to discuss in the public meeting.

After explaining the concept of the urban plan by using VRML image, we asked 19 participants of the public meeting to fill out a questionnaire about the simulation image. On the questionnaire, three questions were asked as the following; 1) Is the explanation with the simulation images made by VR-Terrain easy to understand? 2) Do the houses and buildings simulated by VR-Terrain seem to be real? 3) Do the

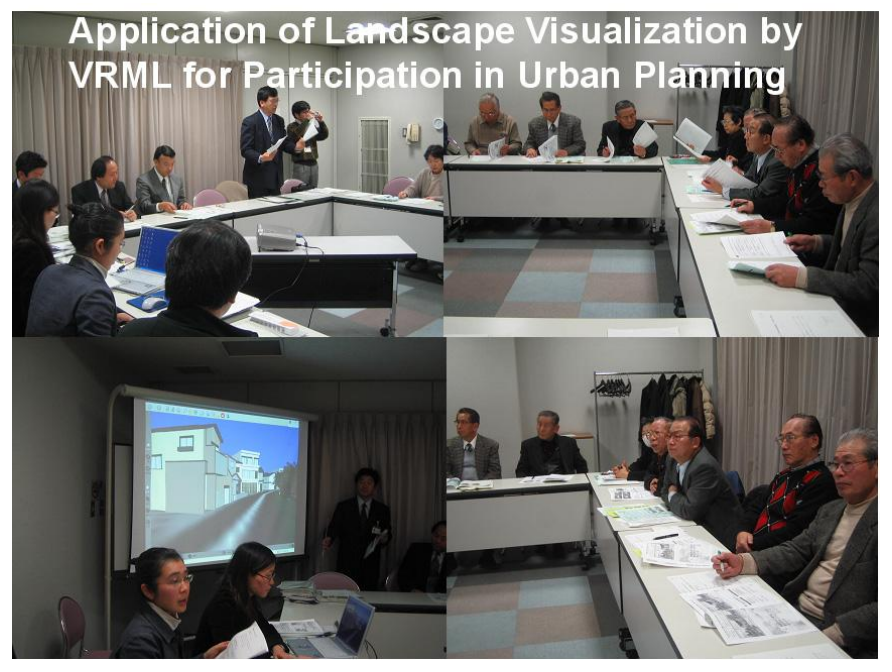

Fig. 16 Photos of the public meeting

images of park made by VR-Terrain seem to be real?

Seventy four percent of participants answered that the explanation was easy to understand. Sixty four percent of participants answered that the houses and buildings made by VR-Terrain seemed real. Forty seven percent of participants answered that the images of park made by VR-Terrain seem real. The above results showed that VR-Terrain has good performance on the visualization of the landscape and the explanation of the landscape planning.

In this study, we conducted the simple questionnaire search the impact of the use of VR for Urban Planning. Lim, et al. conducted landscape assessment experiment both on the Internet and in the laboratory by using VRML images made by VR-Terrain as a stimulus [15]. They showed that the VRML images can be used as an effective stimulus for landscape assessment.

\section{CONCLUSION}

In this study, we developed a landscape visualization system, which we named VR-Terrain, to generate the virtual reality image of landscape by using VRML and plant modeling techniques. In order to test the feasibility of the landscape visualization system, we applied the system to the real process of the Urban Design Plan. We simulated the landscape with about 200 plants and 300 buildings. We used the images simulated by VR-Terrain to explain the concept (such as building height limit) to the residents in the public meetings. We also asked the participants of the public meeting to fill out a questionnaire about the simulation image. Seventy four percent of participants answered that the explanation was easy to understand.

In the public meeting for landscape planning, the fast feed back process from user to planner is important. With the VR-Terrain, fast visualization and fast modification of the planned was possible. The results showed this feed back process by the VRML system effectively helped the public understanding of the concept of the urban design plan. 


\section{ACKNOWLEDGEMENTS}

We would like to thank Mr. Daisuke Kawashima, Chiba University for improving the GUI of VR-Terrain. This study is supported by grants from JSPS (17780019).

\section{REFERENCES}

[1] I. D. Bishop, "Predicting movement choices in virtual environments", Landscape and Urban Planning, 56, 97- 106, 2001.

[2] W. J. Danahy, "Tecnology for dynamic viewing and peripheral vision in landscape visualization", Landscape and Urban Planning. 54, 125 137, 2001.

[3] P. De Reffye, C. Edelin, J. Francon, M. Jaeger and C. Puech, "Plant Models Faithful to Botanical Structure and Development", Computer Graphics, 22, 151-158, 1988.

[4] S. Doyle, M. Dodge and A. Smith, "The potential of web-based mapping and virtual reality technologies for modeling urban environments", Computers, Environment and Urban Systems, Vol. 22, 2, 137-155, 1998.

[5] M. S. Ervin and H. Hasbrouck, "Thirty Years of Computing in Landscape Architecture", Landscape Architecture, 89(11), 54-56, 1999.

[6] D. Fairbairn and S. Parsley, "The Use of VRML for Cartographic Presentation", Computers \& Graphics, Vol. 23, 4, 475-481, 1997.

[7] T. Honjo, "Plant Modeling", The Bulletin of school of High-Technology for Human Welfare Tokai University. Vol. 3, 1-8, 1993.

[8] T. Honjo, K. Saito and Y. Kumagai "A Study of the Application of Plant Modeling and Its Visualization on Landscape Prediction", Journal of the Japanese Institute of Landscape Architecture, 55(5), 301-306, 1992. (In Japanese with English summary)

[9] T. Honjo and S. Takeuchi, "Visualization of Local Environment", The Bulletin of School of High-Tech. Tokai Univ., Vol. 5, 177-181, 1995. (In Japanese with English summary)

[10] T. Honjo and S. Takeuchi, "Method for Three Dimensional Terrain Visualization on Internet", Journal of the Japanese Institute of Landscape Architecture, 61(5), 605-608, 1998. (In Japanese with English summary)

[11] T. Honjo and E. Lim, "Visualization of landscape by VRML system", Landscape and Urban Planning, 55, 175-183, 2001.

[12] B. Huang and H. Lin, "GeoVR: a web-based tool for virtual reality presentation from 2D GIS data", Computers \& Graphics. 25, $1167-1175,1999$

[13] B. Huang and H. Lin, "A Java/CGI approach to developing a geographic virtual reality toolkit on the Internet", Computers \& Graphics. 28, 13-19, 2002.

[14] E. Lim and T. Honjo, "Three-dimensional visualization forest of landscapes by VRML", Landscape and Urban Planning, 63,175-186, 2003.

[15] E. Lim, T. Honjo and K. Umeki, "The validity of VRML images as a stimulus for landscape assessment", Landscape and Urban Planning, 77, 2006, 80-93.

[16] H. Lin, J. Gong and F. Wang, "Web-based three-dimensional geo-referenced visualization", Computers \& Graphics. 25, 1177-1185, 1999.

[17] K. Moore, J. Dykes. and J. Wood, "Using Java to interact with geo-referenced VRML within a virtual field course", Computers \& Graphics, 25, 1125-1136, 1999.

[18] Y. Morimoto, "Computer Visualization of the Vegetation of Katsura Imperial Garden by a Plant Modeling and Visualization System", Journal of the Japanese Institute of Landscape Architecture, 57(5), 113-120, 1993. (In Japanese with English summary)

[19] W. K. Morrison and S. R. Purves, "Customizable landscape visualizations. Implementation, application and testing of a web-based tool", Computers, Environment and Urban Systems, Vol. 22, 6, 529-539, 2002.
[20] A. Muhar, "Three-dimensional modeling and visualization of vegetation for landscape simulation", Landscape and Urban Planning, 54, 5-17, 2001.

[21] B. Orland, "Visualization techniques for incorporation in forest planning geographic information systems", Landscape and Urban Planning, 30, 83-97, 1994

[22] B. Orland, K. Budthimedhee. and J., Uusitalo, "Considering virtual worlds as representations of landscape realities and as tools for landscape planning", Landscape and Urban Planning. 54, 139 - 148, 2001.

[23] J. Raper, T. McCarthy. and N., Williams, "Georeferenced Four-dimensional Virtual Environments: Principles and Applications", Computers, Environment and Urban Systems, Vol. 22, 6, 529-539, 1998.

[24] K. Saito, Y. Kumagai, T. Honjo, Y. Ishida, R. Lecoustre and P. De Reffye, "Photo-realistic Forest Landscape Simulation - Application of GIS and plant modeling technique -“, Nicograph Paper Contest, 9, 226-236, 1993. (In Japanese with an English summary)

[25] L. J. Sipes, "Simulating Natural Phenomena", Landscape Architecture, 84(5), 30-32, 1994

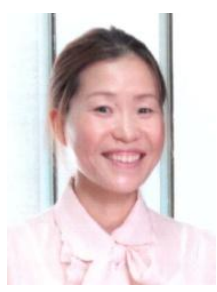

En-Mi Lim, PhD, is an assistant professor in Graduate School of Horticulture at Chiba University, Japan. Her main interest is landscape visualization and landscape assessment by computer graphics and Web 3D. She is also interested in the thermal comfort in urban public places.

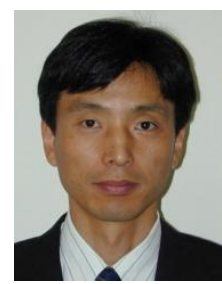

Kiyoshi Umeki, $\mathrm{PhD}$, is an associate professor at Graduate School of Horticulture at Chiba University, Japan. His main interest is in tree ecology and forest ecology. He is also interested in functional-structural tree models.

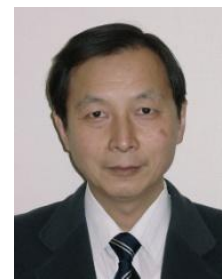

Tsuyoshi Honjo, $\mathrm{PhD}$, is a professor at Graduate School of Horticulture at Chiba University, Japan. One of his interests is visualization of landscape by computer graphics. He is also interested in urban meteorology, especially the effect of urban vegetation. 